УДК 331.101.3

\title{
ИЗУЧЕНИЕ МОТИВАЦИОННОГО ПРОФИЛЯ СОВРЕМЕННОГО РАБОТНИКА КАК ФАКТОРА ПОВЫШЕНИЯ ЭФФЕКТИВНОСТИ ДЕЯТЕЛЬНОСТИ ОРГАНИЗАЦИИ
}

\author{
Ковальчук Оксана Владиславовна \\ старший преподаватель
}

Ганжа Виктория Вячеславовна

ФГБОУ ВО «Владивостокский государственный университет экономики и сервиса», филиал в г. Находке

\begin{abstract}
Аннотация: Эффективная выстроенная система мотивации позволяет руководству организации раскрыть потенциал сотрудников и направлена на оптимальное использование трудовых ресурсов при осуществлении ее производственной деятельности. В то же время, отсутствие или неэффективное построение системы мотивации, приводит к тому, что компания в результате теряет квалифицированных и грамотных сотрудников и как следствие, клиентов и доход. В этой связи анализ мотивационной сферы персонала имеет важное и актуальное значение, так как для того, чтобы эффективно применять мотивационные меры, руководитель должен понимать мотивационную структуру работника и выбирать необходимые стимулы.

Ключевые слова: мотивационный профиль личности, организация, сотрудник, мотивация, методики оценки мотивационного профиля.
\end{abstract}

\section{STUDY OF THE MOTIVATIONAL PROFILE OF A MODERN EMPLOYEE AS A FACTOR IN IMPROVING THE EFFICIENCY OF THE ORGANIZATION}

\section{Koval'chuk Oksana Vladislavovna Ganzha Victoria V.}

\begin{abstract}
Effective built-up motivation system allows the organization's management to unlock the potential of employees and is aimed at optimal use of labor resources in the implementation of its production activities. At the same time, the lack or inefficient construction of a motivation system leads to the fact that the company as a result loses qualified and competent employees and, as a result, 276


customers and income. In this regard, the analysis of the motivational sphere of personnel is important and relevant, since in order to effectively apply motivational measures, the Manager must understand the motivational structure of the employee and choose the necessary incentives.

Key words: motivational profile of a person, organization, employee, motivation, methods of evaluating the motivational profile.

Цель данной статьи заключается в анализе теоретичских подходов изучения мотивационного профиля работника и проведении его диагностики у разных категорий персонала для выявления доминирующих мотивов и их соотношения.

Мотивы, которые побуждают конкретного сотрудника или сотрудников к эффективной работе, могут меняться из-за различных внутренних и внешних воздействий на человека. Поэтому, своевременно проведенный анализ мотивации персонала поможет определить то, насколько сотрудники понимают и удовлетворяют целям организации, а также, в какой степени, это соотносится с удовлетворением их личных потребностей.

Задачами системы мотивации персонала в организации являются:

- ориентировать персонал на решение стратегических задач компании;

- стимулировать эффективную и производительную работу каждого сотрудника;

- привлекать в организацию квалифицированных специалистов и закреплять уже работающих профессионалов;

- стимулировать профессиональное развитие и рост квалификации персонала;

- обеспечивать лояльность сотрудников на всех уровнях и стабильность кадрового состава компании;

- оптимизировать расходы на персонал [1].

Каждый человек имеет свои личные потребности, ценности и приоритеты. Все эти аспекты отражаются в его отношении к работе, именно поэтому мотивация персонала должна быть индивидуальной, прозрачной и понятной для каждого сотрудника. Для разработки индивидуальных методов мотивации персонала используется такое понятие, как «мотивационный профиль». 
Мотивационный профиль - это индивидуальное сочетание стимулирующих факторов человека, которые вдохновляют его выполнять определенные задачи [2, с.17].

Без диагностики сложно сделать выводы о том, чем мотивирован сотрудник, поскольку люди разные и, соответственно, их потребности тоже различаются. Мотив, значимый для одного сотрудника, может никак не повлиять на эффективность труда другого сотрудника. Мотивационный профиль личности в настоящее время рассматривают как удобный и эффективный способ измерения трудовой мотивации.

Выделяют несколько различных методик изучения мотивационного профиля персонала предприятия, которые в основном представлены тестами, опросниками и направлены на диагностику мотивации труда как социального явления, то есть формируют группу социологических методик. Рассмотрим наиболее известные на сегодня методики:

1. Методика «Изучения мотивационного профиля личности» (Ш. Ричи и П. Мартин). Авторы предложили выделить двенадцать основных потребностей сотрудника, которые могут быть использованы как мотиваторы в условиях трудовых коллективов. Для определения индивидуального сочетания наиболее и наименее значимых потребностей для конкретного человека составляется и изучается индивидуальный мотивационный профиль.

2. Методика «Диагностики социально-психологических установок личности в мотивационно-потребительской сфере» (Р.Ф. Потемкиной). Целью этой методики является выявление степени выраженности социальнопсихологических установок. Методика состоит из 80 вопросов, которые направлены на выявление степени выраженности социально-психологических установок «свобода - власть», «труд - деньги».

3. Методика «Диагностика мотивационной структуры личности» (В.Э. Мильман) позволяет составить суждение о рабочей и личной направленности человека. «Направленность личности» - это некоторые устойчивые тенденции личности, такие как общая и творческая активность, стремление к общению, обеспечению комфорта и социального статуса и др.

4. Методика «Диагностики трудовых мотивов» (В.И. Герчиков). Типологическая модель мотивации - это концепция, где говориться о том, что существует пять типов трудовой мотивации: инструментальный, профессиональный, хозяйский, патриотический, избегательный (люмпенский). Модель мотивации строится на пересечении двух осей - 
мотивации и трудового поведения. Различается мотивация достижения и избегания. Мотивацией достижения - стремление получить определенные блага в качестве вознаграждения за трудовую деятельность, а мотивация избегания - это стремление избежать наказания или других негативных последствий за невыполнение поставленных задач или неудовлетворительное исполнение функций.

5. Тестовый комплекс «Структура трудовой мотивации» и «Тест индивидуальной мотивации». Тестовый комплекс «Структура трудовой мотивации» предназначен для экспресс-диагностики структуры мотивационной сферы личности. Тестовые задания построены по принципу парных сравнений по модели «турнир высказываний». Данный комплекс включает две формы - А и В (форма А содержит 12 развернутых формулировок мотивационных конструктов, в которых выражены различные привлекательные стороны трудовой деятельности, форма В отличается от формы А другими формулировками мотивационных диагностических конструктов).

6. Тест-опросник мотивации (Е.А. Куприянова) выявляет существующие как самые эффективные, так и наименее желательные методы стимулирования индивидуально для каждого сотрудника.

7. Тест Ф. Герцберга «Гигиенические и Мотивационные факторы» в адаптации. В двухфакторной теории мотивации упор приходится на систему потребностей «социального человека», основы которой разработаны в рамках теории человеческих отношений. Ф. Герцберг выделил две группы факторов, которые влияют на поведение членов организации: гигиенические и мотивационные. Данная теория появилась из-за растущей необходимости выяснить влияние материальных и нематериальных факторов на мотивацию сотрудников.

8. Методика «Мониторинг трудовых мотивов» (Ф. Герцберга). Согласно методике, эффективная система мотивации персонала должна учитывать актуальные мотивы каждого сотрудника в отдельности и всего коллектива, а для её построения нужно систематически изучать мотивацию и тратить на изучение минимум оплачиваемого рабочего времени [3, с. 86].

Изучив мотивационный профиль каждого работника в организации руководители могут получать ценные знания о мотивах персонала, которые движут работниками и в свою очередь предлагать им стимулы, наиболее соотносящиеся с их мотивацией. 
В рамках данной статьи проведена диагностика мотивационного профиля персонала различных категорий, а именно, специалистов и руководителей кадрового подразделения крупной судоремонтной компании.

В качестве методики диагностики был выбран мотивационный тест Ф. Герцберга, который остается актуальным, достоверным и очень информативным инструментом. С помощью теста можно легко выяснить, что не устраивает сотрудника в текущей ситуации и что его мотивирует. Результаты теста Герцберга используют в самых разных ситуациях - для профессионального ориентирования, при приеме на работу, для оценки уровня напряженности на предприятии. В данном случае диагностика направлена на совершенствование существующей системы мотивации персонала, что обусловлено постоянными изменениями в работе компании и определением новых стратегических ориентиров.

Данная теория Ф. Герцберга выделяет две группы факторов мотивации: гигиенические и мотивационные.

Гигиенические факторы - это те минимальные удобства, которыми предприятие должно обеспечивать сотрудника.

К таким факторам относят:

- экономические (зарплата, премии, отпуск, социальные и пенсионные льготы, оплата компанией обучения и повышения квалификации);

- физические (условия труда, расположение рабочего места, его оформление, температура, освещение, чистота, предписания);

- социальные (отношения в коллективе, отдых на праздники);

- статус (престижность работы, титулы и привилегии, оценка труда);

- ориентация (отчеты и различные собрания, беседы);

- безопасность (как физическая, так и социальная).

При выполнении минимума факторов гигиены достигается нейтральное отношение сотрудников к своей работе. Если же факторов недостаточно, то формируется негативное отношение к работе. То есть, если сотруднику будет комфортно, то он этого не замечает. Но небольшой признак дискомфорта сразу заставляет обратить на себя внимание. Если сотрудника устраивает зарплата, условия труда, коллектив, корпоративная культура, то он воспринимает это как должное и обычное дело, а, следовательно, не выражает никаких положительных эмоций по этим факторам. Несоблюдение хоть одного из факторов может вызывать множество отрицательных эмоций у сотрудника.

Мотивационные факторы - связаны с характером и сущностью самой работы, они побуждают сотрудников больше и эффективнее выполнять свои 
должностные обязанности, они не вызывает неудовлетворения, но и не повышают работоспособность сотрудников.

Их наличие вызывает положительное восприятие работы и удовлетворение ею.

К ним относят:

- премии за достижения;

- п предоставление свободы действий;

- д доступ к информации;

- карьерный рост;

- определенная ответственность;

- планирование;

- использование накопленного опыта;

- суть самой работы;

- признание;

- сотрудничество [4, с.146].

Прохождение теста позволит узнать наиболее важные для отдельного сотрудника мотивы.

Для определения мотивационного профиля сотрудников, анализа их степени мотивации в ПАО «НСРЗ» был проведен опрос на основании методики «мотивационного профиля» Ф. Герцберга. В предоставленном тесте приняли участие 2 руководителя и 10 сотрудников. Опрашиваемым предоставлены 27 вопросов, каждый из которых представляет собой пару противоположных друг другу ситуаций. Сотрудник должен оценить их, исходя из того, какое утверждение ему больше всего подходит. Итоги прохождения сотрудниками теста указаны на рисунке 1.

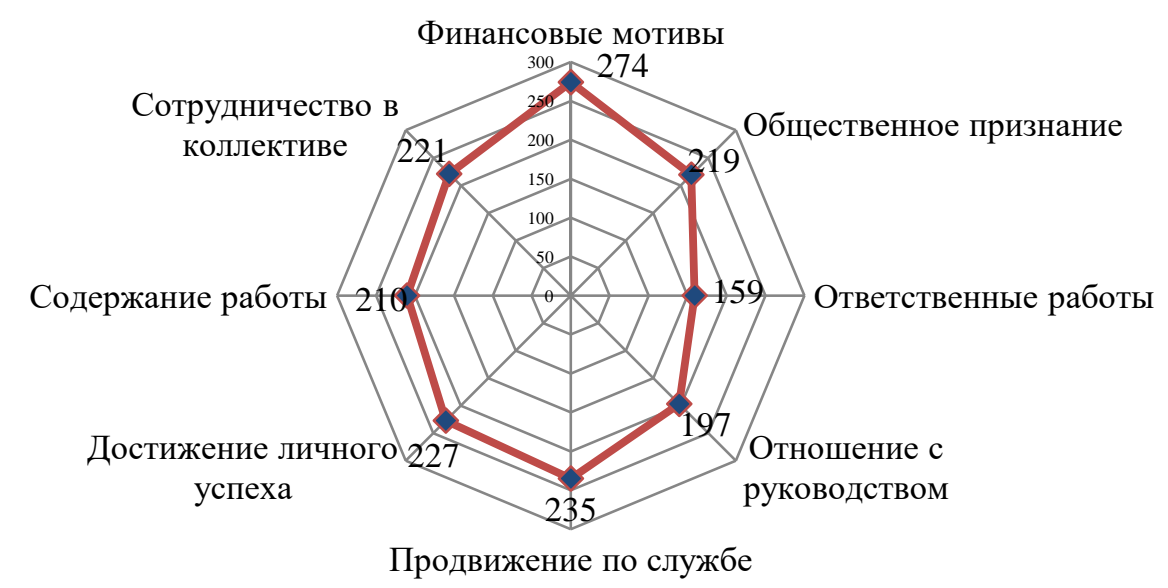

Рис. 1. Результаты опроса сотрудников по методике

Ф. Герцберга, [составлено авторами] 
Исходя из результатов опроса, было выявлено, что лидирующее место из основных потребностей персонала занимают финансовые мотивы, а именно заработная плата и материальное вознаграждение (274 балла). Это объясняется тем, что именно хорошая зарплата позволяет им удовлетворить важные и необходимые потребности. Финансовое мотивирование важно для сотрудников более молодого возраста, так как именно в этом возрасте наибольший уровень приобретений, что сопряжено с финансовыми затратами. Так же хорошая заработная плата для всех сотрудников является важным стимулом для достижения высоких результатов в работе.

Второе место занимает продвижение по службе (235 балов). Продвижение по карьерной лестнице - это важный элемент роста и личностного совершенствования сотрудника. Профессиональные успехи, новые знания и навыки, управленческое мастерство создают новое самоощущение сотрудника и его восприятие в глазах коллег и партнеров. А так же необходимо учитывать то, что с повышением в должности увеличивается и уровень заработной платы сотрудника.

Третье место занимает фактор достижения личного успеха (227 балов). Это можно объяснить тем, что сотрудники готовы трудиться, чтобы достичь высоких результатов в работе. В этом случае сотрудники, за счет собственного осознания своих достижений, будут удовлетворять свою внутреннюю потребность в значимости. А получив соответствующее стимулирование за свою работу от вышестоящего руководства, у сотрудника будет развиваться желание дальше эффективно и качественно выполнять поставленные перед ним задачи.

Так же третье место разделяет фактор сотрудничества в коллективе (221 бал). Это означает, что работа в коллективе немаловажна для сотрудников. В коллективе у сотрудников развивается чувство принадлежности к организации, они чувствуют себя одним целым. Сотрудники начинают понимать цели и задачи не только своей работы, но и всей организации в целом. За счет коллективных решений определенных задач, сотрудники могут развиваться, обучаться новому, участвовать в обсуждении проблем и поиске их решений.

Так же, при принятии решений сотрудники ориентируются не только на свои ценности, но и на ценности всей организации. Сотрудникам легко подчинить свои желания общей задаче, расставить приоритеты в пользу 
общего результата, сделать больше, чем от них ожидают, и озвучить свое видение ситуации.

Можно заметить еще и тот факт, что общественное признание уступает сотрудничеству в коллективе всего лишь в 2 балла. То есть, можно сделать вывод, что сотрудники, выполняя свою работу, ожидают, что их заслуги будут замечены и оценены по достоинству. И связывая две эти потребности, можно сказать, что сотрудники, работая в коллективе и получая общественное признание, будут более мотивированы на эффективную работу.

Далее следуют потребности, занимающее среднее значение: содержание работы (210 балов), отношение с руководством (197 балов), и последнее место занимают ответственные работы (159 балов).

Результаты в оценке мотива «потребности в содержании работы» говорят о том, что сотрудники не стремятся разнообразить свой трудовой процесс. Они не заинтересованы в изменении своей трудовой деятельности, их устраивает те функции, которые они выполняют на занимаемой должности, а однообразие в выполнении работ является обычным делом. Для таких сотрудников главное - стабильность и гарантированность рабочего места.

Также сотрудники не заинтересованы в формировании и поддерживании доверительных взаимоотношений с руководством. Им предпочтительнее заниматься своими делами и обязанностями, а пересекаться с руководством только в случае появления рабочих проблем и вопросов.

Низкий балл за «выполнение ответственных работ» говорит о том, что сотрудники организации не стремятся брать на себя ответственность, то есть выполнять более сложную и разнообразную работу.

На основе анализа полученных результатов можно заметить основные пробелы в мотивации персонала и разработать мероприятия по их решению. Только учитывая особенности внутренней среды организации, руководитель может эффективно управлять трудовым потенциалом персонала.

Далее, на рисунке 2, представлены результаты опроса руководителей организации.

В опросе приняло участие два руководителя. 


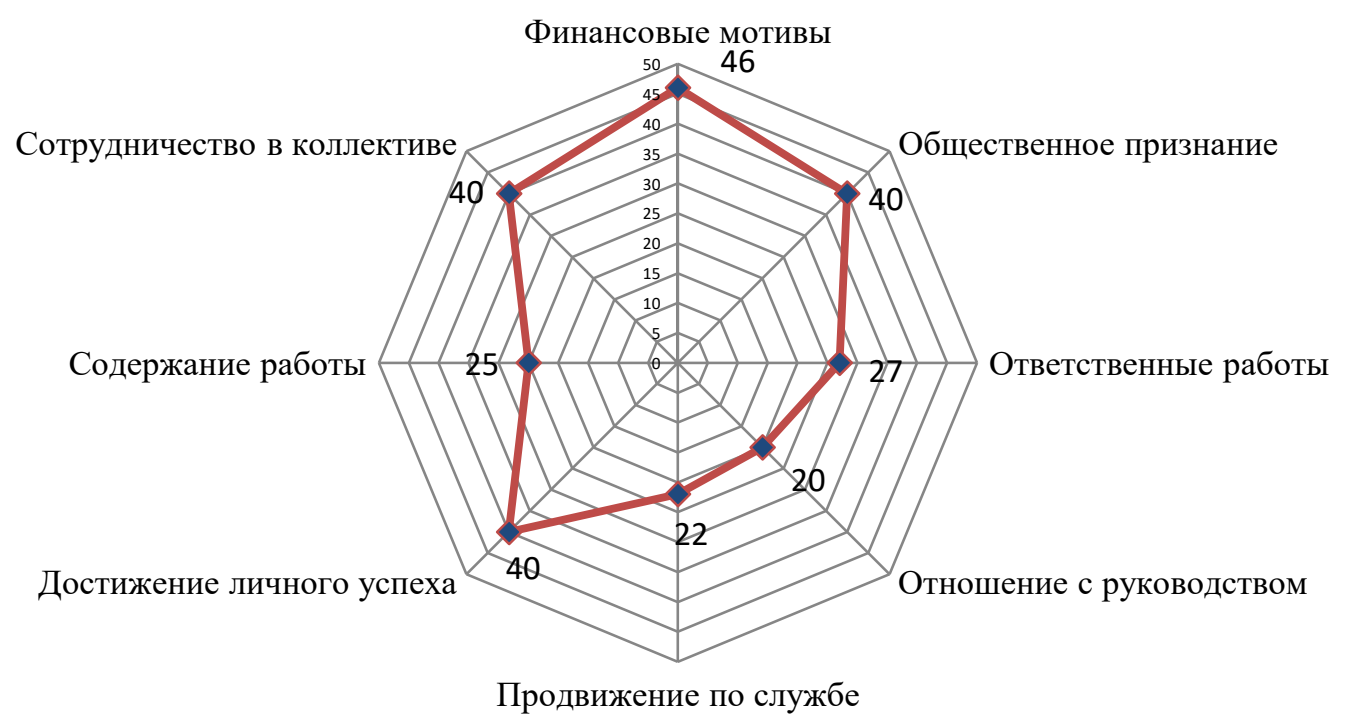

\section{Рис. 1. Результаты опроса руководителей по методике Ф. Герцберга, [составлено авторами]}

По данным результатам можно сделать вывод, что приоритетными лидирующими потребностями для руководителей также как и для специалистов являются финансовые мотивы (46 балов), но уже на второй план выходят мотивы общественного признания (40 балов), сотрудничества в коллективе (40 балов) и достижения личного успеха (40 балов). Это можно объяснить тем, что имея высокую должность (т.е. уже поднявшись по карьерной лестнице), руководитель старается заслужить доверие и уважение коллектива, показать себя с лучшей стороны. Такое отношение к коллективу может способствовать сплочению подчиненных и более эффективному выполнению своих трудовых обязанностей.

Так же, второе место разделяет мотив достижения личного успеха. Имея высокую, хорошо оплачиваемую должность, человек старается не просто выполнять свои должностные обязанности и цели организации, но и самосовершенствоваться, развиваться, выполнять работу, которая в дальнейшем приведет к высоким результатам личного успеха.

Третье место можно поделить между мотивом «ответственные работы» (27 балов) и «содержанием работ» (25 балов). Это говорит о том, что руководителей беспокоит содержание их трудовой деятельности, они больше мотивированы на решение сложных задач и не боятся брать на себя ответственность за их выполнение. 
Низкие показатели выявлены в «заинтересованности отношений с руководством» (22 бала) и «продвижение по службе» (20 балов). В этой связи можно сделать вывод о том, что руководители больше ориентированы на взаимоотношения с подчиненными, чем с вышестоящим руководством. В случае с недостаточной мотивацией с продвижением по карьерной лестнице, можно предположить, что для руководителей среднего уровня управления дальнейший вертикальный карьерный рост затруднен. Это может свидетельствовать о возможном отсутствии программы формирования кадрового резерва на предприятии, что снижает мотивацию руководителей.

Так как, осознавая шанс дальнейшего продвижения, руководитель стремиться совершенствовать свои знания и навыки, повышать свою квалификацию.

Подводя общий итог по данному опросу можно сказать, что финансовая мотивация преобладает как у обычных служащих, так и руководителей. Так как, именно, денежное вознаграждение помогает в большей степени удовлетворить все необходимые потребности. Далее, трудовые мотивы у руководителей и служащих немного расходятся. У служащих - преобладают потребности в продвижении по карьерной лестнице, достижении личного успеха и сотрудничества в коллективе, а у руководителей в общественном признании, достижении личного успеха и ответственных работах.

Таким образом, можно заключить, что на основе изучения различных методик, изложенных в данной работе, была выбрана методика тестирования «Гигиенические и Мотивационные факторы» Ф. Герцберга для составления мотивационного профиля сотрудников компании. Результаты проанализированы, и в дальнейшем, полученные данные помогут скорректировать существующую систему мотивации с учетом выявленных особенностей. Это приведет как к повышению эффективности работы сотрудников исследуемого подразделения компании, так и всей организации в целом.

\section{Список литературы}

1. Мотивационный профиль личности как основа обеспечения удовлетворенности работой и мотивации [Электронный ресурс] / Интернет pecypc. - 2019. - Режим доступа: http:/hr-portal.ru (Дата обращения: 19.10.2020).

2. Б. Трейси. Мотивация: учебник / Б. ТрейсиА. Манн, Н.Д. Иванов и Н. Фербер. - М.: КниРус, 2016. - 126 с. 
3. Уткин Э. А. Основы мотивационного менеджмента: учебник / Э.А. Уткин. - М.: ЭКМОС, 2017. - 352 с.

4. Ф. Герцбер. Мотивационный профиль персонала: учеб.пособие для вузов / Ф. Герцберг: пер. с англ. проф. Е.А. Климовым. - М.: ЮНИТИ-ДАНА, 2004. - 399 с. - (Серия «Зарубежный учебник»). 